\title{
A Transcodificação Numérica em Crianças com Indícios de Discalculia do Desenvolvimento
}

\section{Numerical Transcoding in Childrean with Evidence of Developmental Dyscalculia}

\section{Lanúzia Almeida Brum Avilaa ; Isabel Cristina Machado de Lara ${ }^{a}$}

a Departamento de Educação em Ciências e Matemática, Pontifícia Universidade Católica do Rio Grande do Sul, Porto Alegre, Brasil - lanuzia.avila@acad.pucrs.br, isabel.lara@pucrs.br

\author{
Palavras-chave: \\ Transcodificação \\ numérica. Discalculia do \\ desenvolvimento. \\ Repotencialização. \\ Habilidades \\ matemáticas. \\ Intervenções \\ psicopedagógicas.
}

Resumo: Este artigo apresenta alguns resultados advindos de uma pesquisa de Mestrado sobre o desempenho de crianças com indícios de Discalculia do Desenvolvimento, utilizando-se como um dos instrumentos para a avaliação, o Teste de Transcodificação. O objetivo é analisar a repotencialização de habilidades matemáticas relacionadas à transcodificação numérica - $\mathrm{TN}$, após o período de intervenções psicopedagógicas. A pesquisa ocorreu em dois momentos: a avaliação de 13 crianças com idades entre 9 e 12 anos e reavaliação das crianças, após o período de 10 sessões de intervenções. Para analisar os resultados obtidos, seguiu-se o indicado pela literatura do teste e realizou-se o Teste $t$ de Student. A partir dos resultados numéricos, gráficos e tabelas foram construídos com a pretensão de ilustrar as variações no desempenho em relação às habilidades de cada uma das crianças. Após a análise do pós-teste, verifica-se que, de modo geral, as crianças apresentaram melhoras.

\section{Keywords:}

Numeric transcoding.

Developmental dyscalculia. Repowering. mathematical skills. Psychopedagogical interventions.

\begin{abstract}
This article presents some results from a Master's research on the performance of children with signs of Developmental Dyscalculia, using as one of the instruments for the evaluation, the Transcoding Test. The objective is to analyze the repotencialization of mathematical abilities related to numerical transcoding $\mathrm{TN}$, after the period of psychopedagogical interventions. The research took place in two moments: the evaluation of 13 children aged 9 to 12 years and reassessment of the children, after the period of 10 sessions of interventions. To analyze the results obtained, we followed the indicated in the literature of the test and the Student's tTest was performed. From the numerical results, graphs and tables were constructed with the aim of illustrating the variations in the performance in relation to the abilities of each one of the children. After the analysis of the post-test, it was verified that, in general, the children presented improvements.
\end{abstract}




\section{Introdução}

O Transtorno de Aprendizagem em Matemática - TAM, mais conhecido como Discalculia do Desenvolvimento - DD vem sendo estudado desde a década de 1940, quando foi definida por Gerstmann (1957) como sendo uma inabilidade em relação às operações simples e/ou complexas, dificuldade em compreender a orientação da sequência dos numerais e as frações.

Corroborando essa definição, Bakwin (1960 apud KOSC, 1974) refere-se à DD como uma dificuldade em contar. Posteriormente, Cohn (1961 apud MYKLEBUST; JHONSON, 1962) e Gerstmann (1940 apud MYKLEBUST; JHONSON, 1962), mencionaram a DD como sendo ocasionada por uma disfunção cerebral, referente ao reconhecimento e manipulação de numerais.

Em uma tentativa de sistematizar uma definição de DD, Myklebust e Jhonson (1962), destacam que:

Em crianças em idade escolar esta condição muitas vezes se manifesta por uma incapacidade em aritmética, embora a inteligência e outros aspectos do comportamento estão dentro de um intervalo normal. Alguns conceitos em aritmética são deficientes, alguns não podem ler numerais e, portanto, não podem escrevê-los. Outros não podem associar o significado com os símbolos que indicam o processo aritmético a ser empregado, como $=, \mathrm{x} \mathrm{e}+{ }^{l}$ (MYKLEBUST; JHONSON, 1962, p.14, tradução nossa).

Com base nos estudos anteriores, Kosc (1970 apud KOSC, 1974) conceitua DD como sendo:

[...] é uma disfunção estrutural de habilidades matemáticas, que tem sua origem numa deficiência genética ou congênita dessas partes do cérebro, que são os substratos anatômico-fisiológicos diretos da maturação das habilidades matemáticas de acordo com a idade, sem uma disfunção simultânea de funções mentais gerais ${ }^{2}$ (KOSC, 1970, p. 192 apud KOSC, 1974, p. 165, tradução nossa).

Nessa perspectiva, Haase et al. (2011) definem DD como entidade nosológica, comprometendo habilidades relacionadas aos cálculos e ao processamento numérico. A incidência desse transtorno é entre $3 \%$ e $6 \%$, atingindo estudantes no período escolar, envolvendo problemas em relação ao conceito do número, habilidades de contagem em

\footnotetext{
1 "In school children this condition often is manifested by an obvious disability in arithmetic although intelligence and other aspects of behavior are well within the normal range. Some are deficient in arithmetical concepts, some cannot read numbers and hence, cannot write them. Others cannot associate meaning with the symbols which indicate the arithmetical process to be employed, such as =, X and +" (MYKLEBUST; JHONSON, 1962, p.14).

2 "[...] is a structural disorder of mathematical abilities which has its origin in a genetic or congenital disorder of those parts of the brain that are the direct anatomico-physiological substrate of the maturation of the mathematical abilities adequate to age, without a simultaneous disorder of general mental functions" (KOSC, 1970, p. 192 apud KOSC, 1974, p. 165).
} 
defasagens, dificuldades relacionadas à transcodificação numérica e problemas na resolução de cálculos envolvendo as quatro operações (HAASE et al., 2011).

Bastos (2006) reforça essa ideia afirmando que a DD, pode ser compreendida como "[...] uma dificuldade em aprender matemática, com falhas para adquirir proficiência adequada neste domínio cognitivo, a despeito de inteligência normal, oportunidade escolar, estabilidade emocional e motivação necessária." (BASTOS, 2006, p. 202).

$\mathrm{Na}$ intenção de criar um sistema uniforme para definir e classificar as habilidades em defasagem na DD, Kosc (1974) propôs uma classificação em seis categorias: Discalculia verbal; Discalculia practognóstica; Discalculia léxica; Discalculia gráfica; Discalculia ideognóstica; Discalculia operacional. A seguir apresentam-se as habilidades em prejuízo em cada categoria (KOSC, 1974).

Discalculia verbal. "É manifestada pela perturbada habilidade de designar verbalmente termos e relações matemáticas, como nomear quantidades e números de coisas, dígitos, numerais, símbolos operacionais, e performances matemáticas ${ }^{3}$ " (KOSC, 1974, p. 167, tradução nossa).

Discalculia practognóstica. "Nesses casos, há uma disfunção na manipulação matemática de objetos reais ou em figuras (dedos, bolas, cubos, bastões, etc. $)^{4 \text { ", }}$ (KOSC, 1974, p. 167, tradução nossa).

Discalculia léxica. "Essa disfunção em particular está relacionada a uma deficiência em ler símbolos matemáticos (dígitos, números, sinais de operações, e operações matemáticas escritas $)^{5 "}$ (KOSC, 1974, p. 167, tradução nossa).

Discalculia gráfica. "É uma deficiência em manipular símbolos matemáticos na escrita, análoga à discalculia léxica ${ }^{6}$ " $($ KOSC, 1974, p. 167-168, tradução nossa).

Discalculia ideognóstica. "Essa é uma deficiência primariamente em entender ideias e relações matemáticas e fazer cálculos mentais"77 (KOSC, 1974, p. 168, tradução nossa).

Discalculia operacional. Nesse caso, a habilidade de manipular operações matemáticas é diretamente perturbada ${ }^{8, "}$ (KOSC, 1974, p. 168, tradução nossa).

\footnotetext{
${ }^{3}$ Verbal Dyscalculia. "Is manifested by the disturbed ability to designate verbally mathematical terms and relations, such as naming amounts and numbers of things, digits, numerals, operational symbols, and mathematical performances" (KOSC, 1974, p. 167).

4 "In these cases there is a disturbance of mathematical manipulation with real or pictured objects (fingers, balls, cubes, staffs, etc.)” (KOSC, 1974, p. 167).

${ }^{5}$ Lexical Dyscalculia. "This particular disorder is concerned with a disability in reading mathematical symbols (digits, numbers, operational signs, and written mathematical operations) $)^{5, "}$ (KOSC, 1974, p. 167).

${ }^{6}$ Graphical Dyscalculia. "This is a disability in manipulating mathematical symbols in writing, analogous to lexical dyscalculia" (KOSC, 1974, p. 167-168).

${ }^{7}$ Ideognostical Dyscalculia. "This is a disability primarily in understanding mathematical ideas and relations and in doing mental calculation" (KOSC, 1974, p. 168).

${ }^{8}$ Operational dyscalculia. "In this case, the ability to carry out mathematical operations is directly disturbed Discalculia operacional (KOSC, 1974, p. 168). 
A necessidade de caracterização de diferentes subtipos de DD, é destacada por Haase et al. (2011, p. 273): "Há muito a fazer pela caracterização da DC [Discalculia] com vistas a diminuir o impacto negativo grave da discalculia sobre o desenvolvimento infantil".

A caracterização da DD, a qual Haase et al. (2011) referem-se encontra-se na definição do DSM-V (2014, p. 67), “[...] um termo alternativo usado em referência a um padrão de dificuldades caracterizado por problemas no processamento de informações numéricas, aprendizagem de fatos aritméticos e realização de cálculos precisos ou fluentes.”.

Nesse sentido, Avila e Lara (2017) reportam-se à DD como um Transtorno de Aprendizagem - TA, que acomete as habilidades específicas, necessitando avaliação e tratamento psicopedagógico. Conforme as autoras (2017),

[...] a falta de instrumentos de avaliação capazes de proporcionarem com precisão que tipo de habilidade está em defasagem e a escassez de literatura sobre esse transtorno, dificulta a atividade desse profissional impedindo-o, muitas vezes, de realizar intervenções que de fato reabilitem as habilidades debilitadas (AVILA; LARA, 2017, p. 53).

Considerando a relevância desse tema, constituiu-se, em 2015, o Grupo de Estudos e Pesquisas sobre Discalculia - PUCRS, coordenado pela professora Dra. Isabel Cristina Machado de Lara, dando início a diferentes estudos e pesquisas. Assim, este artigo é um recorte de uma pesquisa de Mestrado em Educação em Ciências e Matemática, intitulada como "Avaliação e intervenções psicopedagógicas em crianças com indícios de Discalculia".

Para delimitar este artigo apresenta-se os resultados advindos do Teste de Transcodificação (MOURA et al., 2013), o qual foi utilizado como um dos instrumentos de avaliação psicopedagógica, aplicado em 13 crianças com idades entre 9 e 12 anos e reaplicado para reavaliação, após o período de intervenção. O objetivo é "Analisar a repotencialização de habilidades matemáticas relacionadas à transcodificação numérica, em crianças com indícios de Discalculia, após o período de intervenções psicopedagógicas".

\section{Transcodificação numérica}

Freitas et al. (2012) referem-se à Transcodificação Numérica - TN, como sendo um processo que envolve habilidades em transcodificar representações diversas dos números. Segundo os autores, a representação verbal para a arábica, estaria correlacionada ao ditado de números, já a representação arábica para a verbal, envolveria a leitura em voz alta dos números (FREITAS et al., 2012).

No que se refere à representação verbal, Silva et al. (2015) mencionam que está relacionada ao modelo de código triplo proposto por Dehaene (1992), o qual precisa 
explicações condizentes ao processamento numérico ${ }^{9}$. Freitas et al. (2012) destacam que o código verbal é utilizado na transcodificação, na contagem e na recuperação de fatos aritméticos.

Em relação ao modelo de código triplo Dehaene e Cohen (1995) destacam que:

Um modelo é proposto para os processos mentais e os circuitos neuroanatômicos envolvidos no processamento mental do número na aritmética. $\mathrm{O}$ modelo elaborado por Dehaene (1992) modelo de código triplo, assume que as representações arábicas e de magnitude dos números estão disponíveis para ambos os hemisférios, mas que a representação verbal que está subjacente à recuperação de fatos aritméticos é disponível apenas para o hemisfério esquerdo. São propostas especulações como substratos anatômicos e conexões destas representações (DEHAENE; COHEN, 1995, p. 83, tradução nossa).

Segundo Freitas et al. (2012), na intenção de explicar a TN, nos últimos anos diversos modelos cognitivos tem sido propostos. Conforme os autores, os modelos podem ser classificados em: a) modelos semânticos, os quais estão relacionados à representação de magnitude e de quantidade dos números; b) modelos assemânticos, os quais não consideram a representação de magnitude e de quantidade dos números (FREITAS et al., 2012).

No que diz respeito ao modelo semântico, Freitas et al. (2012) ressaltam que:

O modelo semântico mais influente e utilizado é o Modelo Semântico-lexical de Power e Dal Martello (1990), o qual postula a representação semântica como sendo baseada no código de entrada verbal (Longuet-Higgins, 1978). Primeiramente, a compreensão do processo ocorre no momento em que o número verbalmente percebido é transformado em uma representação semântica (FREITAS et al., 2012, p. 4).

Barrouilet, Camos, Perruchet e Seron (2004) desenvolveram o modelo Assemântico de Desenvolvimento Processual da Transcodificação - ADAPT, o respectivo modelo supõe que a aprendizagem dos números ocorre por meio: das regras necessárias para a transcodificação de números com dois dígitos; da adição de novas regras de transcodificação de números maiores; do abandono dos processos anteriores para a recuperação da memória de trabalho.

No que concerne ao ADAPT, Freitas et al. (2012) mencionam que no modelo em questão, a sequência verbal correspondente ao numeral:

[...] é armazenada temporariamente no buffer fonológico. Um processo de análise compara com essa sequência de representação unidades armazenadas na memória de longo prazo. Caso não seja possível toda a cadeia ser processada de uma só vez [...] um processo de análise isola as unidades que podem ser processadas pelo sistema de produção. Separadores (mil e cem) são usados para identificar o número de dígitos necessários para a forma digital da sequência verbal [...] O processo de análise de determinada parte da sequência verbal é interrompido logo que a forma digital de um segmento está disponível na memória de longo prazo e sua forma digital é armazenada na memória de trabalho (FREITAS et al., 2012, p. 4-5).

\footnotetext{
${ }^{9} \mathrm{O}$ sistema de processamento de números compreende os mecanismos de compreensão e produção de números, enquanto o sistema de cálculo consiste nos fatos e procedimentos exigidos especificamente para a realização de cálculos (MCCLOSKEY; CARAMAZZA, 1985, p. 173, tradução nossa).
} 
Com o objetivo de avaliar os aspectos correlacionados à $\mathrm{TN}$, em particular as habilidades envolvidas na leitura e na escrita de 28 números de um a quatro dígitos, foi elaborado por Moura et al. (2013) o instrumento designado Teste de Transcodificação. Na primeira etapa do teste, busca-se avaliar as habilidades de representação numérica para o código verbal, por meio da leitura dos números. Enquanto na segunda etapa do teste, o objetivo é avaliar os aspectos envolvidos nas habilidades da escrita dos números, ou seja, a representação do código verbal para o código arábico, mediante ao ditado dos números (FREITAS et al., 2012).

Além disso, segundo Moura et al. (2013), os erros na transcodificação são classificados em erros lexicais e sintáticos. Os erros lexicais consistem em erros de 1-2 dígitos e de 3-4 dígitos, em que um elemento léxico é substituído por outro (exemplos: 47, a criança lê como quarenta e cinco; vinte e cinco, a criança escreve como 28) (MOURA et al., 2013).

Já em relação aos erros sintáticos, são classificados em erros de 1-2 dígitos e de 3-4 dígitos, os elementos léxicos são usados corretamente, mas erroneamente alocados na sequência do numeral, ou quando a magnitude dos números é alterada, mas os elementos léxicos permanecem corretos. Os erros sintáticos estão ligados à extensão do numeral, onde existe a necessidade de aplicação de regras de codificação de lugar (exemplos: 5962 a criança lê como cinco mil seiscentos e noventa e dois; mil e trezentos escrito como 1000300).

Convém destacar, que os erros sintáticos em se tratando da leitura dos números, são classificados em: erro de multiplicando: 400 a criança lê como quatro mil; fragmentação da cadeia numérica: 567 a criança lê como cinco e seis e sete; omissão de elementos: 1900 a criança lê como novecentos; erro de valor posicional: 160 a criança lê como mil e seis; elementos trocados: 432 a criança lê como quatrocentos e vinte e três. No que se refere à escrita dos números, os erros sintáticos são classificados em: elemento intruso: setecentos a criança escreve como 7003; omissão de elementos: mil e quinze a criança escreve como 15; elementos trocados: três mil setecentos e noventa e um a criança escreve como 3719 (MOURA et al., 2013).

De acordo com Moura et al. (2013), os erros sintáticos podem estar relacionados a falhas de memória de trabalho ou de aplicação das regras; enquanto os erros lexicais podem estar relacionados a déficits no léxico numérico ou no acesso a ele (exemplos: dezenove a criança escreve como 15; 246 a criança lê como duzentos e quarenta e cinco). Esse déficit pode estar ligado a uma fraca exposição aos símbolos numéricos (MOURA et al., 2013).

Desse modo, Moura et al. (2013) destacam que crianças com Dificuldades de Aprendizagem em Matemática - DAM, nos primeiros anos, lutam com as propriedades lexicais. Os autores (2013) têm como hipótese, que nas propriedades lexicais as crianças evitam ou tem pouca exposição aos numerais e em se tratando das propriedades sintáticas, as 
crianças sem dificuldades lutam apenas contra essas. Nos anos seguintes, o domínio das propriedades lexicais se assemelha aos controles e restam apenas dificuldades no domínio das propriedades sintáticas.

A comparação realizada pelos autores (2013) por meio da amostra entre as crianças de $3^{\circ}$ e $4^{\circ}$ ano testadas em sua pesquisa, com o objetivo de investigar as habilidades de transcodificação em crianças brasileiras com e sem DAM, mostrou que não há diferença na transcodificação dos números entre os grupos, em se tratando dos erros lexicais. Contudo, há diferenças quanto aos erros sintáticos (MOURA et al., 2013).

\section{Métodos de pesquisa}

Com o objetivo de "Analisar a evolução do desenvolvimento das habilidades matemáticas envolvidas na Discalculia de crianças com indícios desse transtorno, após a realização de intervenções psicopedagógicas" foi utilizado, na pesquisa, a qual deu origem ao presente artigo, como método de pesquisa a abordagem qualitativa e quantitativa.

Considerando a possibilidade de oportunizar aos participantes a reabilitação e potencialização das habilidades matemáticas em defasagem na $\mathrm{DD}$, adotou-se como delineamento do método quantitativo, a pesquisa experimental.

Flick (2007) diferencia os métodos quantitativos dos qualitativos, afirmando que os primeiros podem ser definidos como atalhos da pesquisa de dados, enquanto os qualitativos podem ser capazes de propiciar explicações científicas dos acontecimentos.

Contudo, o autor defende a ideia de que os dois métodos podem unir-se de variadas formas durante as diferentes fases do processo de pesquisa, tornando-se possível unir as pesquisas qualitativa e quantitativa de forma pragmática e reflexiva (FLICK, 2007).

Yin (2010, p. 161) corrobora a questão da utilização da pesquisa de abordagem qualitativa-quantitativa, enfatizando que:

Determinados estudos [...] podem incluir quantidades substanciais de dados qualitativos. Se esses dados forem submetidos às análises estatísticas ao mesmo tempo em que os dados qualitativos permanecem [...] você terá conseguido, com sucesso, uma forte estratégia analítica.

Em relação ao método de pesquisa, Creswell (2010) menciona que com o desenvolvimento da pesquisa qualitativa e da pesquisa quantitativa, tanto nas ciências humanas como sociais, ganhou espaço a pesquisa de métodos mistos, em que acontece a combinação de ambos os métodos. Conforme o autor (2010, p. 238):

[...] os problemas abordados pelos pesquisadores das ciências sociais e da saúde são complexos, e o uso de abordagens quantitativas em sí é inadequado para lidar com essa complexidade [...] uso combinado proporciona uma maior compreensão dos problemas de pesquisa. 
O autor (2010) salienta que os métodos mistos são menos conhecidos do que as abordagens quantitativas e qualitativas. Eles surgiram em 1959 com Campbell e Fisk, utilizando em sua pesquisa múltiplos métodos, no intento de estudar os traços psicológicos. A iniciativa dos pesquisadores incentivou outros a combinarem ambos os métodos. Entretanto, foi na década de 1990 que evoluiu a combinação dos métodos qualitativo e quantitativo (CRESWELL, 2010).

Foi pensando nisso que essa abordagem foi escolhida, se por um lado pretendeu-se analisar qualitativamente a anamnese, e os resultados de cada criança nos testes, por outro se fez relevante apresentar uma análise quantitativa por meio do uso de testes estatísticos e de gráficos, com o sentido de perceber aclives e declives no desempenho de cada criança. Vale ressaltar, que além dos gráficos, se buscou resultados estatísticos fornecidos por meio de testes, neste estudo, o Teste $t$ de Student para variâncias iguais e para amostras pareadas.

Além disso, adotou-se a pesquisa experimental, por ser frequentemente utilizada nas ciências humanas, em específico acerca de estudos envolvendo aprendizagem em pequenos grupos de sujeitos (GIL, 2010).

Gil (2010, p. 47) explica que a pesquisa experimental "[...] consiste em determinar um objeto de estudo, selecionar as variáveis que seriam capazes de influenciá-lo, definir as formas de controle e de observação dos efeitos que a variável produz no objeto". Para o autor, esse tipo de pesquisa, tem grande prestígio nos meios científicos e propicia ao pesquisador atuar ativamente e não apenas como observador dos participantes da pesquisa.

Conforme o autor (2010), esse tipo de pesquisa pode ser realizada em qualquer ambiente e não necessariamente apenas em laboratórios, como popularmente acredita-se que fosse. Entretanto, conforme Gil (2010, p. 32) para que seja desenvolvida a pesquisa experimental, faz-se necessário as propriedades a seguir:

[...] manipulação: o pesquisador precisa fazer alguma coisa para manipular pelo menos uma das características dos elementos estudados [...] controle: o pesquisador precisa introduzir um ou mais controles na situação experimental, sobretudo criando um grupo de controle [...] distribuição aleatória: a designação dos elementos para participar dos grupos experimentais e de controle deve ser feita aleatoriamente.

Nesse sentido, o autor (2010) aponta a pesquisa experimental, como sendo a mais valiosa fonte de informação aos cientistas na testagem de hipóteses, em que se estabelecem relações entre causa e efeito nas variáveis. Esse tipo de experimento permite garantia demasiada perante outros tipos de delineamento, devido às possibilidades de controle.

\section{Seleção dos participantes da pesquisa}

O presente estudo, advindo da pesquisa "Avaliação e intervenções psicopedagógicas em crianças com indícios de Discalculia”, obteve aprovação do comitê de ética em pesquisa da Universidade, em que a pesquisa foi desenvolvida. 
A amostra desse estudo é composta por 13 participantes, na faixa etária entre 9 anos e 12 anos e 11 meses e escolaridade a partir do $3^{\circ}$ ano dos anos iniciais do Ensino Fundamental. Nesta pesquisa, cada participante é denominado por Criança 1, Criança 2, ..., no intuito de preservar sua identidade.

Os dados da amostra foram advindos de três maneiras. Seis crianças, por meio da iniciativa de seus responsáveis, buscaram a avaliação pelo projeto Avaliação de Crianças em Risco de Transtornos de Aprendizagem - ACERTA realizada no ambulatório do Hospital São Lucas da PUCRS. Perfazendo as etapas abaixo:

- encaminhamento de e-mail pelos pais ou responsáveis pelo participante para projetoacerta@gmail.com, mencionando o interesse de seu(ua) filho(a) participar da pesquisa;

- triagem por meio de contato telefônico, em que foram salientados os critérios de inclusão na pesquisa, bem como a faixa etária entre 9 anos e 12 anos e 11 meses, estar frequentando escola regular a partir do $3^{\circ}$ ano dos anos iniciais e ler e escrever palavras com sílabas simples;

- anamnese com os pais ou responsáveis e triagem quanto ao processo de leitura, escrita e memória de trabalho;

- Teste de Transcodificação (MOURA et al., 2013);

- Subteste de Aritmética (STEIN, 1994);

- Escala Wechsler Abreviada de Inteligência - WASI (2014);

- avaliação com a fonoaudióloga;

- devolução do diagnóstico referente ao processo de leitura e escrita.

Além disso, realizou-se uma busca ao banco de dados do projeto ACERTA, com o objetivo de verificar as crianças com hipótese diagnóstica de Dislexia e com DAM, as quais foram relatadas pelos responsáveis na anamnese. Selecionou-se 17 crianças, perfazendo as etapas a seguir:

- triagem por meio de contato telefônico, em que foram salientados os critérios de inclusão na pesquisa, bem como a faixa etária entre 9 anos e 12 anos e 11 meses, estar frequentando escola regular a partir do $3^{\circ}$ ano dos anos iniciais e apresentar DAM;

- anamnese detalhada acerca da Matemática;

- Teste de Transcodificação (MOURA et al., 2013);

- Subteste de Aritmética (STEIN, 1994).

Adicionado a essas duas formas de coleta dos dados, realizou-se uma triagem psicopedagógica com estudantes de duas escolas públicas de Capivari do Sul. Tal triagem desenvolveu-se por meio das seguintes etapas:

- anamnese detalhada acerca da Matemática;

- Teste de Transcodificação (MOURA et al., 2013); 
- Subteste de Aritmética (STEIN, 1994);

- Escala Wechsler Abreviada de Inteligência - WASI (2014).

Após o aceite de participação da pesquisa, as crianças e seus responsáveis, assinaram o Termo de Assentimento e o Termo de Consentimento Livre e Esclarecido, em ambas as etapas, avaliação e intervenção psicopedagógica, em duas vias, sendo uma, entregue aos participantes da pesquisa.

$\mathrm{Na}$ primeira etapa do estudo, foram avaliadas 29 crianças com indícios de DD, a partir dos resultados dos testes, realizou-se o contato telefônico com os responsáveis, em que foram salientados os critérios de inclusão para a segunda etapa, das intervenções psicopedagógicas. Desses 29 participantes da pesquisa, os responsáveis por 15 crianças aceitaram continuar participando da pesquisa, entretanto duas delas foram excluídas no decorrer do período das intervenções, por apresentarem transtornos emocionais (omitidos pelo responsável durante a anamnese), os quais poderiam interferir em relação às habilidades matemáticas.

Posteriormente, organizou-se dois grupos de participantes, o grupo controle, composto por seis crianças e o grupo experimental, com nove crianças iniciando-se assim, o processo de intervenção psicopedagógica. Das nove crianças do grupo experimental, sete delas concluíram o processo de intervenção. Os participantes de ambos os grupos, foram selecionados com base nas avaliações das testagens matemáticas realizadas anteriormente e nos critérios da pesquisa, verificando aqueles com indícios de DD.

Em relação às intervenções com o grupo controle, que ocorreram no período de $10 \mathrm{de}$ outubro de 2016 a 29 de novembro de 2016. Foram realizadas cinco aulas, com 2 horas de duração cada uma, na sala de recursos de uma escola estadual do Município de Capivari do Sul, duas vezes por semana, no turno da manhã e da tarde. Posteriormente, foram realizadas cinco sessões individuais, com 2 horas de duração cada uma, realizadas no mesmo espaço da escola.

As intervenções com o grupo experimental, ocorrerem no período de 28 de setembro de 2016 a 18 de novembro de 2016. Foram realizadas 10 sessões, com 1 hora de duração cada uma, no Laboratório de Aprendizagem da Matemática da Faculdade de Matemática da PUCRS, no Prédio 30, sala 208, no turno manhã e tarde.

Vale ressaltar, que para esta pesquisa, o teste de QI foi realizado com todas as crianças no ambulatório do Hospital São Lucas da PUCRS, todos os testes e intervenções realizados com o grupo experimental foram desenvolvidos no Laboratório de aprendizagem da Matemática da Faculdade de Matemática da PUCRS, enquanto os testes e intervenções com o grupo controle foram realizados no âmbito de uma sala de recursos de uma escola estadual do Município de Capivari do Sul. 
Este artigo limita-se à apresentação dos resultados obtidos no Teste de Transcodificação (MOURA et al., 2013) das 13 crianças participantes no pré-teste e no pósteste, após o período das intervenções.

\section{Instrumentos para coleta de dados}

$\mathrm{Na}$ intenção de coletar os dados necessários neste estudo, utilizou-se para a coleta de dados: anamnese com os responsáveis; Escala Wechsler Abreviada de Inteligência - WASI (2014); Teste de Transcodificação; Intervenções psicopedagógicas; Reavaliação psicopedagógica.

\section{Anamnese com os responsáveis}

A anamnese $\mathrm{e}^{10}$ foi realizada com todos os responsáveis pela criança e foi aplicada pelos bolsistas de iniciação científica incluídos no projeto ACERTA, no intuito de buscar dados acerca da queixa principal das DA, do desenvolvimento do participante desde o nascimento, dados sobre a saúde física e mental, questões escolares e familiares importantes e quanto à rotina do estudante.

Após a seleção dos grupos, controle e experimental, uma anamnese detalhada acerca da Matemática foi reaplicada pela pesquisadora.

\section{Escala Wechsler Abreviada de Inteligência - WASI (2014)}

No projeto ACERTA, já estava previsto a realização no ambulatório de DA à avaliação psicológica, o QI estimado, sendo aplicado por um(a) psicólogo(a), a Escala Wechsler Abreviada de Inteligência - WASI (2014), tendo como critério para inclusão na pesquisa QI acima ou igual a 85.

\section{Teste de Transcodificação (MOURA et al., 2013)}

O Teste de Transcodificação foi aplicado com os 13 participantes desta pesquisa, em duas etapas. Na primeira etapa, foi solicitada a criança que realizasse a leitura dos números apresentados. Um total de 28 números escritos no sistema indo-arábico de um a quatro dígitos foi apresentado aos estudantes, um de cada vez. Solicitando-se a leitura em voz alta.

Posteriormente, na segunda etapa, solicitou-se que a criança realizasse a escrita dos números no sistema indo-arábico. Nesse momento, foi entregue um protocolo, com espaços reservados para escrever 28 números ditados pela pesquisadora, um a um. O teste foi

\footnotetext{
${ }^{10}$ Vale ressaltar que este documento foi elaborado pelos membros do projeto ACERTA, tendo questões expandidas, elaboradas pela pesquisadora e sua orientadora, para avaliar especificamente a história de cada criança acerca das possíveis dificuldades na disciplina de Matemática.
} 
reaplicado com as 13 crianças, após o período das intervenções psicopedagógicas e os resultados foram analisados, seguindo padronização do próprio teste.

\section{Intervenções psicopedagógicas com o grupo controle e o grupo experimental}

As intervenções do grupo controle foram conduzidas pela pesquisadora, em num total de cinco encontros, duas vezes por semana. Para cada um dos encontros, foram elaboradas aulas acerca de conteúdos matemáticos, ministradas de um modo mais tradicional, com metodologias diferenciadas daquelas do grupo experimental, porém com a utilização de jogos, material concreto e exercícios. O intuito foi apresentar metodologias mais próximas daquelas vivenciadas pelos estudantes no seu dia-a-dia escolar. Para verificar as práticas pedagógicas que faziam parte do cotidiano desses estudantes realizou-se uma conversa informal com as professoras titulares.

Após a reavaliação, os participantes do grupo controle que avançaram e descartaram os indícios de DD foram dispensados. Os demais, ainda com os indícios, receberam as mesmas 10 horas de intervenção do grupo experimental.

Em relação às sessões de intervenção do grupo experimental foram conduzidas pela pesquisadora, em um total de 10 encontros, duas vezes por semana. Para cada um dos encontros foram elaborados diferentes jogos pedagógicos buscando dar conta do desenvolvimento das habilidades matemáticas envolvidas na DD.

Tendo como ênfase o jogo como instrumento mediador na relação entre os sujeitos, foram confeccionados pelas pesquisadoras alguns jogos de raciocínio, priorizando as habilidades em defasagem de cada uma das crianças e considerando as seis categorias de Kosc (1974), com o objetivo de oportunizar as crianças o desenvolvimento de habilidades emocionais, cognitivas, sociais e éticas. Com base nos jogos, teve-se como meta que a criança buscasse estratégias para solucionar problemas, aprendendo a lidar com o erro e desenvolver a consciência de seu processo de raciocínio. No total foram 38 jogos elaborados pela pesquisadora, 11 jogos selecionados do livro de Lara (2011).

\section{Resultados}

A apresentação dos resultados seguiu a seguinte ordem: (1) resultados do grupo controle, referente ao desenvolvimento das habilidades matemáticas dos estudantes, após as intervenções psicopedagógicas em grupo; (2) resultado referente ao desenvolvimento das habilidades matemáticas dos participantes da pesquisa do grupo controle, os quais permaneceram com indícios de DD e realizaram as intervenções psicopedagógicas individuais; (3) resultados do grupo experimental, referente ao desenvolvimento das 
habilidades matemáticas dos estudantes, após o período de intervenções psicopedagógicas individuais.

Os resultados no grupo controle, referente ao desenvolvimento das habilidades matemáticas das crianças advieram, num primeiro momento, de atividades e jogos propostos ao final dos encontros que evidenciaram ou não o resgate das habilidades matemáticas não detectadas no diagnóstico inicial. A partir desses resultados, os que permaneceram com os indícios de DD receberam as intervenções individuais, a fim de terem acesso às mesmas intervenções que o grupo experimental. Ao final de todas as intervenções, todos os participantes da pesquisa, passaram pela reavaliação psicopedagógica com os mesmos instrumentos de avaliação iniciais.

\section{Reavaliação psicopedagógica}

A reavaliação psicopedagógica foi executada por três examinadoras, após o período de intervenções psicopedagógicas realizadas com os participantes, na intenção de "Analisar a repotencialização de habilidades matemáticas relacionadas à transcodificação numérica, em crianças com indícios de Discalculia, após o período de intervenções psicopedagógicas”.

Para tanto, foi reaplicado, o Teste de Transcodificação (MOURA et al., 2013).

\section{Método de análise}

O levantamento dos dados do Teste de Transcodificação (MOURA et al., 2013) é feito computando-se os erros, em relação a etapa um, leitura dos números e etapa dois, escrita dos números; categorizando os erros em lexical (1-2 dígitos), sintático (1-2 dígitos), lexical (3-4 dígitos) e sintático (3-4 dígitos). A soma dos erros do teste é denominada Escore Bruto (EB). O EB máximo no Teste de Transcodificação é de 28 erros em cada uma das etapas.

A partir dos resultados numéricos obtidos, foram construídos gráficos com o intuito de ilustrar de modo mais nítido possíveis variações nesses desempenhos. Para validar estatisticamente os resultados realizou-se o Teste $t$ de Student para variâncias iguais e para amostras pareadas, adotando-se como valor-p $<0,05$.

Referente ao Teste $t$, Haianaut (1997, p. 192) denomina-o como sendo um método que possibilita "[...] decidir se a diferença observada entre as médias de duas amostras se pode atribuir a uma causa sistemática, ou se pode ser considerada como efeito das flutuações devidas ao acaso.”. Verifica-se assim, se as amostras foram retiradas da mesma população. 


\section{Sobre as intervenções psicopedagógicas}

Dentre os 49 jogos elaborados para realização das intervenções psicopedagógicas, são apresentados neste artigo, apenas uma quantidade suficiente para que se perceba o modo como tais intervenções foram desenvolvidas.

Escolheram-se 10 jogos levando em conta exemplificar como atividades lúdicas podem abordar as categorias de DD apontadas por Kosc (1974).

\section{Jogo 1 - Brincando com as caixas}

Habilidades: Que a criança seja capaz de: manipular objetos; quantificar os objetos associando os respectivos números; nomear os numerais e números; representar por meio de desenhos, conjuntos de quantidades e números por escrito.

Recursos: numerais de zero a nove em E.V.A; um jogo de 10 caixas com quantidades diferentes de objetos em cada uma, variando de zero a nove; folhas de ofício.

Regras do jogo: A criança receberá 10 caixas e ao sinal dado pela psicopedagoga, deverá iniciar a contagem dos objetos que estão dentro de cada caixa e encontrar os numerais que compõem os números correspondentes a cada uma das caixas e grudá-los nas mesmas, nomeando verbalmente cada um deles. Ao término do jogo, a psicopedagoga deverá solicitar à criança que faça a representação das caixas com os objetos, por meio de conjuntos escrevendo os seus respectivos números, na folha de ofício.

Potencialidades do jogo: Esse jogo oportuniza ao mediador potencializar e reabilitar as habilidades da Discalculia practognóstica, da Discalculia verbal e da Discalculia gráfica:

a) ao realizar a contagem dos objetos e encontrar os números correspondentes a cada uma das caixas e grudá-los nas mesmas, a criança estará ampliando suas habilidades de enumeração, manipulando os objetos e associando os numerais aos números correspondentes - Discalculia practognóstica;

b) ao nomear os números que representam respectivas quantidades, a criança estará verbalizando oralmente - Discalculia verbal;

c) ao fazer a representação das caixas com os objetos, na folha de ofício, por meio de conjuntos de quantidades e de números por escrito, a criança estará escrevendo símbolos matemáticos - Discalculia gráfica.

\section{Jogo 2 - Classificando as crianças}

Habilidades: Que a criança seja capaz de: classificar objetos, percebendo cada vez mais um número maior de atributos; diferenciar classes e subclasses de objetos; quantificar objetos; realizar inclusões; realizar interseções.

Recursos: um jogo estruturado: oito meninas e oito meninos.

Regras do jogo: A psicopedagoga deverá colocar sobre a mesa o material para as crianças manusearem, após iniciará os questionamentos: 1 - O que tu estás vendo? 2 - Como 
tu podes organizar esse jogo? 3 - Como tu pensaste? 4 - Existe outra maneira? Como tu pensaste? 5 - Existe ainda outra maneira? (Até esgotar todas) 6 - Como tu pensaste? 7 - O que têm mais, meninas ou meninos? Por que? 8 - O que têm mais, crianças ou meninas? Por que? 9 - O que têm mais, crianças de roupa azul ou roupa laranja? Por que? 10 - O que têm mais, crianças de roupa laranja ou meninas de roupa laranja? Por que? O que têm menos, meninos ou crianças? Por que? 11 - O que têm menos, meninos ou meninos de sapato verde? Por que? 12 - O que têm mais, crianças de sapato roxo ou crianças de roupa azul? Por que? 13 - O que têm mais, crianças de roupa azul ou meninas? Por que? 14 - O que têm mais, crianças com cabelo preto ou crianças de sapato verde? Por que?

Potencialidades do jogo: Esse jogo oportuniza ao mediador potencializar e reabilitar habilidades da Discalculia verbal e da Discalculia practognóstica:

a) ao classificar os objetos conforme seus atributos, por meio das perguntas realizadas pela psicopedagoga, a criança estará diferenciando as classes e subclasses verbalizando oralmente

\section{- Discalculia verbal;}

b) ao realizar inclusões e intersecções quanto às classificações dos grupos e subgrupos, quantificando em relação a mais e a menos, a criança estará manipulando e enumerando os objetos - Discalculia practognóstica.

\section{Jogo 3 - Jogando dominó com os blocos lógicos ${ }^{11}$}

Habilidades: Que a criança seja capaz de: desenvolver o vocabulário fundamental da Matemática; nomear, termos e relações matemáticas; reconhecer os diferentes atributos de cada peça do material; criar relações entre as peças desenvolvendo seu raciocínio lógico.

Recursos: uma caixa com Blocos Lógicos.

Regras do jogo: A psicopedagoga deverá distribuir igualmente as peças com a criança. Se sobrarem peças, elas deverão ficar na caixa para serem compradas. A psicopedagoga solicitará que a criança coloque uma peça na mesa e posteriormente, fará o mesmo procedimento, colocando ao lado (como no tradicional jogo de dominó) uma peça que possua um mesmo atributo explicando o porquê de sua escolha. O próximo jogador poderá colocar sua peça em qualquer um dos extremos, dizendo também o atributo escolhido. Quando um dos jogadores não tiver mais peças para colocar, deverá comprar uma nova peça, caso não tenha passa a vez. O jogo terminará, quando um dos jogadores colocar a sua última peça.

Potencialidades do jogo: Esse jogo oportuniza ao mediador potencializar e reabilitar as habilidades da Discalculia verbal:

${ }^{11}$ LARA, Isabel Cristina Machado. Jogando com a Matemática. São Paulo: Editora Rêspel, 2005. p. 47-49. 
a) ao nomear verbalmente os diferentes atributos de cada uma das peças dos Blocos Lógicos, criando relações entre as peças, a criança estará verbalizando oralmente - Discalculia verbal.

\section{Jogo 4 - Construindo o número ${ }^{12}$}

Habilidades: Que a criança seja capaz de: nomear números, símbolos e relações matemáticas; ordenar os números de zero a nove; compreender a inclusão hierárquica; construir redes de relações numéricas.

Recursos: um jogo estruturado (torres de um a nove) com caixas de fósforo pequenas; um dado com 10 faces enumeradas de zero a nove (dodecaedro).

Regras do jogo: A psicopedagoga solicitará que a criança lance o dado, pegue a peça que representa aquela quantidade e, monte todas as torres possíveis com outras peças que dê o mesmo resultado da torre sorteada. A cada rodada, a psicopedagoga fará perguntas sobre a ordem e inclusão hierárquica para verificar se, de fato, a criança já construiu ou está construindo o número.

Potencialidades do jogo: Esse jogo oportuniza ao mediador potencializar e reabilitar habilidades da Discalculia verbal e da Discalculia practognóstica:

a) ao pegar a peça que representa a quantidade do dado e montar todas as torres possíveis com o mesmo resultado da torre sorteada, a criança estará nomeando, ordenando, enumerando e comparando números - Discalculia verbal e Discalculia practognóstica.

\section{Jogo 5 - Jogando com os dados}

Habilidades: Que a criança seja capaz de: nomear verbalmente os números; desenvolver habilidades relacionadas à grafia dos símbolos e o valor posicional dos numerais.

Recursos: dois dados com seis faces em E.V.A; quadro valor de lugar; uma caixa de material Base 10.

Regras do jogo: A psicopedagoga solicitará que a criança lance os dados. O primeiro dado lançado representará o numeral da unidade e o segundo o numeral da dezena, que deverão ser representados por sua escrita no quadro valor de lugar. Após, a criança deverá representar o número formado com o material Base 10. Em seguida, a psicopedagoga realizará o mesmo procedimento.

Potencialidades do jogo: Esse jogo oportuniza ao mediador potencializar e reabilitar habilidades da Discalculia verbal e da Discalculia gráfica:

a) ao nomear os números verbalmente, a criança estará desenvolvendo habilidades orais -

\section{Discalculia verbal;}

b) ao registrar no quadro valor de lugar os numerais, a criança estará potencializando habilidades vinculadas à grafia dos símbolos e o valor posicional dos numerais - Discalculia gráfica.

${ }^{12}$ LARA, Isabel Cristina Machado. Jogando com a Matemática. São Paulo: Editora Rêspel, 2005. p. 77-79. 


\section{Jogo 6 - Matemática florida ${ }^{13}$}

Habilidades: Que a criança seja capaz de: compreender a inclusão hierárquica; reconhecer a escrita dos algarismos; construir quantidades a partir de outras duas; construir redes de relações numéricas.

Recursos: 30 "pétalas" na forma hexagonal contendo adições; cinco "miolos" na forma hexagonal com numerais de cinco a nove e uma "pétala" em branco.

Regras do jogo: A psicopedagoga irá entregar para a criança um "miolo", seis "pétalas" e uma "pétala" em branco e ficará um "miolo" e seis "pétalas". Cada jogador deverá encaixar as "pétalas" no seu miolo, se ela resultar no numeral representado. O jogo iniciará com o jogador que recebeu uma peça a mais mostrando suas cartas, viradas para si, ao outro jogador, para que retire uma das "pétalas", sem ver, e tente encaixar. Após, será a vez da psicopedagoga e assim sucessivamente, até um dos jogadores conseguirem montar sua flor.

Potencialidades do jogo: Esse jogo oportuniza ao mediador potencializar e reabilitar habilidades da Discalculia léxica e da Discalculia ideognóstica:

a) no decorrer das jogadas, quando a criança reconhecer a escrita dos algarismos, estará realizando a leitura de símbolos matemáticos - Discalculia léxica;

b) ao construir quantidades a partir de outras, formando redes de relações numéricas, a criança estará realizando cálculos mentais e percebendo a inclusão hierárquica, organizando mentalmente as operações de adição - Discalculia ideognóstica.

\section{Jogo 7 - Tabuleiro da adição e da subtração ${ }^{14}$}

Habilidades: Que a criança seja capaz de: desenvolver conceitos de adição; resolver operações envolvendo adições; desenvolver o raciocínio lógico.

Recursos: um tabuleiro na forma triangular com 25 triângulos desenhados cada um contendo resultados; 25 peças triangulares cada uma contendo uma expressão matemática envolvendo adição ou subtração.

Regras do jogo: A psicopedagoga deverá entregar à criança o tabuleiro, e as 25 peças, solicitando que resolva a expressão indicada na peça e encaixe no tabuleiro, no qual estará o resultado.

Potencialidades do jogo: Esse jogo oportuniza ao mediador potencializar e reabilitar as habilidades da Discalculia léxica e Discalculia ideognóstica:

a) ao longo do jogo quando a criança reconhecer as operações matemáticas por meio da leitura dos 25 triângulos estará realizando a leitura de símbolos matemáticos - Discalculia léxica;

\footnotetext{
${ }^{13}$ LARA, Isabel Cristina Machado. Jogando com a Matemática. São Paulo: Editora Rêspel, 2005. p. 87.

${ }^{14}$ LARA, Isabel Cristina Machado. Jogando com a Matemática. São Paulo: Editora Rêspel, 2005. p. 111-112.
} 
b) ao realizar as adições e subtrações, na intenção de encaixar os triângulos e montar o tabuleiro, a criança estará realizando cálculos mentais, organizando mentalmente as operações

\section{- Discalculia ideognóstica.}

\section{Jogo 8 - Torre das operações}

Habilidades: Que a criança seja capaz de: resolver operações envolvendo adição e subtração; formalizar o conceito de adição e subtração.

Recursos: 20 copos em acrílico com operações; quatro bolas coloridas; folha de registro dos cálculos; material Base 10.

Regras do jogo: A psicopedagoga solicitará que a criança jogue a bola, na tentativa de derrubar o maior número possível de copos, caso não consiga derrubar nenhum dos copos, terá mais três tentativas. A cada rodada os jogadores deverão fazer o registro das operações na folha e com o apoio do material Base 10, resolver as operações. Após, será a vez da psicopedagoga realizar a sua jogada. O jogo chegará ao final, quando as 30 operações forem resolvidas.

Potencialidades do jogo: Esse jogo oportuniza ao mediador potencializar e reabilitar habilidades da Discalculia gráfica e da Discalculia operacional:

a) ao resolver as operações na folha de registro, a criança estará realizando o registro dos algoritmos, desenvolvendo habilidades relacionadas à escrita dos símbolos e o valor posicional dos numerais - Discalculia gráfica e Discalculia operacional.

\section{Jogo 9 - Multiplicando ovos}

Habilidades: Que a criança seja capaz de: realizar operações mentais envolvendo multiplicação; compreender conceitos matemáticos, organizando seu pensamento e seu raciocínio lógico.

Recursos: uma bandeja de ovos grandes numerada do um ao 30; um dado com seis faces em E.V.A; dois marcadores em formato de "galinha"; um quadro para cada jogador.

Regras do jogo: A psicopedagoga solicitará que a criança lance o dado e de acordo com o número deverá andar com a galinha o número de casas no tabuleiro. Posteriormente, a psicopedagoga pedirá que a criança multiplique o número do dado pelo número da casa em que parar, realizando o registro pictórico e a escrita numérica de ovos a cada rodada. Em seguida, a psicopedagoga realizará o mesmo procedimento e assim sucessivamente. O jogo terminará quando um dos jogadores chegar à casa 30 do tabuleiro. Ao término do jogo, ambos os jogadores farão a contagem dos pontos que obtiveram ao longo das jogadas.

Potencialidades do jogo: Esse jogo oportuniza ao mediador potencializar e reabilitar habilidades da Discalculia ideognóstica e da Discalculia gráfica: 
a) ao realizar a resolução das operações mentalmente, a criança estará desenvolvendo habilidades de compreensão dos conceitos matemáticos, sendo necessário organizar seu pensamento e seu raciocínio lógico - Discalculia ideognóstica;

b) ao fazer o registro pictórico e a escrita numérica de ovos a cada rodada, a criança estará representando símbolos matemáticos - Discalculia gráfica.

\section{Jogo 10 - Caixa de laranjas}

Habilidades: Que a criança seja capaz de: aprimorar habilidades relacionadas ao pensamento de divisão partitiva; organizar seu pensamento proporcional demonstrando reversibilidade.

Recursos: um saquinho com cartelas de numerais do um ao 10; 10 caixas pequenas; 100 laranjas em E.V.A; um quadro para cada jogador.

Regras do jogo: A psicopedagoga solicitará que a criança retire do saquinho um numeral, o qual representará o número de caixas e após, separe algumas laranjas, as quais deverão ser distribuídas nas caixas. Em seguida, a criança deverá distribuir igualmente o número de laranjas nas caixas e realizar o registro pictórico no quadro. Em seguida, a psicopedagoga realizará o mesmo procedimento e assim sucessivamente. É necessário que a criança separe um número de laranjas maior do que o número sorteado para a quantidade de caixas.

Potencialidades do jogo: Esse jogo oportuniza ao mediador potencializar e reabilitar habilidades da Discalculia ideognóstica e da Discalculia gráfica:

a) ao distribuir igualmente o número de laranjas entre as caixas, a criança estará desenvolvendo habilidades relacionadas à compreensão da divisão participativa e estimulando o seu pensamento proporcional e o pensamento reversível, compreendendo conceitos matemáticos - Discalculia ideognóstica;

b) ao fazer o registro pictórico do número de caixas, do número de laranjas, do total de laranjas em cada caixa e do número de laranjas que restaram a cada rodada, a criança estará representando símbolos matemáticos - Discalculia gráfica.

\section{Análise dos resultados}

$\mathrm{Na}$ intenção de analisar e comparar a evolução de cada uma das crianças em relação a sua performance, identificando possíveis avanços relacionados às habilidades matemáticas dos dois grupos de crianças com indícios de DD, apresenta-se os resultados obtidos, por meio de gráficos e pelo Teste $t$ de Student, para variâncias iguais e para amostras pareadas.

Para ilustrar e sintetizar as modificações no desempenho das crianças do grupo controle submetidas às intervenções psicopedagógicas, elaborou-se os Gráficos 1 e 2. 
Gráfico 1 - Total de números com erros no Teste de Transcodificação - leitura - pré-teste com pós-teste 1 e 2:

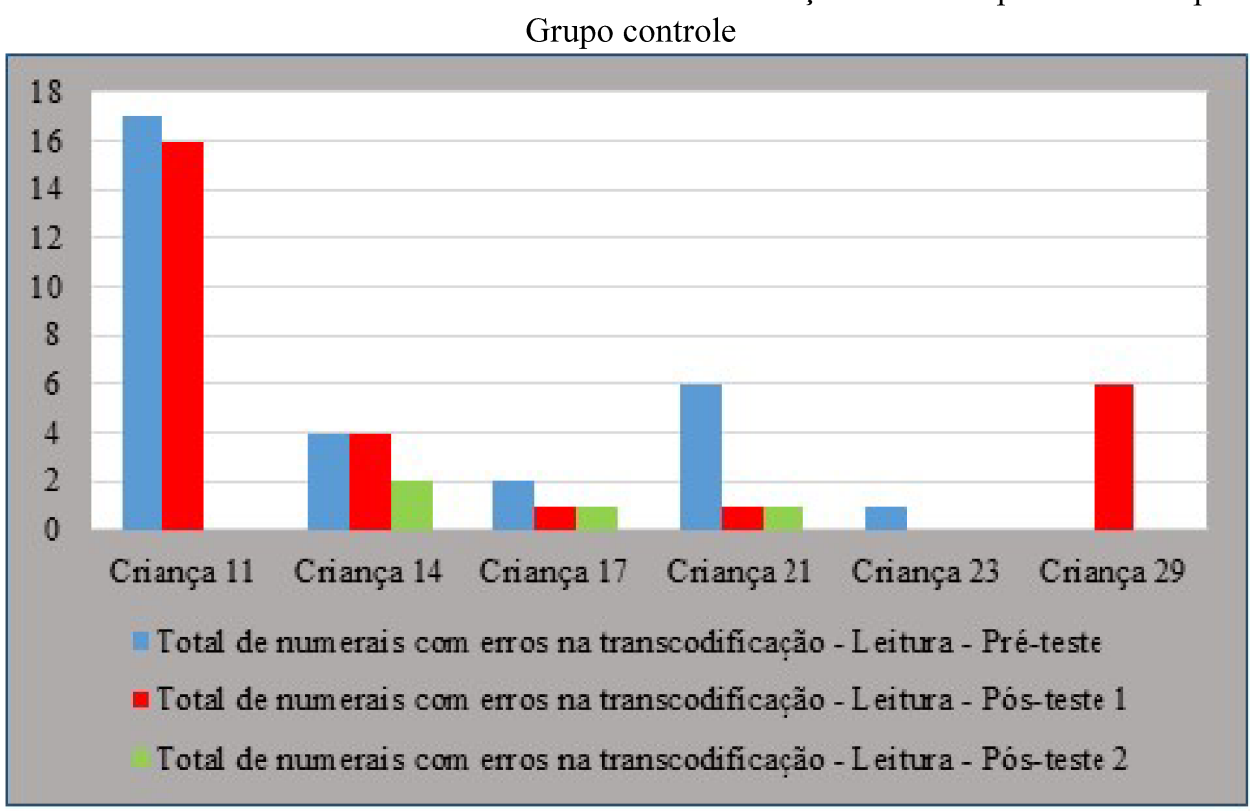

Fonte: Elaborado pelas autoras.

Convém destacar que as crianças 11 e 29 realizaram apenas as intervenções em grupo, descartando os indícios de DD, devido às questões emocionais. Com base nos resultados desse gráfico, é visível que em relação à leitura de números, quando considerado os resultados do pré-teste com o pós-teste 1, que houve uma pequena melhora de quatro crianças, já com as intervenções em grupo. Entretanto, quando comparado os resultados do pré-teste com o pós-teste 2, considerando apenas as quatro crianças 14, 17, 21 e 23, as quais permaneceram com os indícios de DD, detectou-se um crescimento em seus desempenhos na leitura dos números. Convém destacar ainda, que as crianças 17 e 23, possuem como hipótese diagnóstica de dificuldades de aprendizagem - DA em leitura e escrita e que as crianças 14 e 29, apresentam hipótese diagnóstica de Dislexia, verificado no processo de avaliação multidisciplinar do projeto ACERTA, provavelmente essas habilidades em prejuízo na DA e na Dislexia interferiram negativamente nos resultados de transcodificação da leitura dos números.

Com a intenção de validar as hipóteses levantadas e apontadas na análise do Gráfico 1, elaborou-se as Tabelas 1 e 2, apresentando os resultados obtidos por meio do Teste $t$ para amostras pareadas, adotando como valor de significância para limiares de $t$ a probabilidade $<5 \%$.

Tabela 1 - Teste $t$ para o Teste de Transcodificação - leitura - pré-teste com pós-teste 1: Grupo controle

\begin{tabular}{lcccc}
\hline & Média & $\begin{array}{c}\text { Número de } \\
\text { participantes }\end{array}$ & $\begin{array}{c}\text { Desvio } \\
\text { padrão }\end{array}$ & Valor-p (<0,05) \\
\hline Pré-teste & 5 & 6 & 6,26 & 0,41 \\
Pós-teste 1 & 4,67 & 6 & 5,99 & \\
\hline
\end{tabular}

Fonte: Elaborado pelas autoras. 
Com base na Tabela 1, do ponto de vista estatístico, observa-se que não houve diferenças significativas, em relação ao desempenho das crianças do grupo controle quando comparado os resultados do pré-teste com o pós-teste 1, após o período das intervenções psicopedagógicas em grupo, verificando-se assim que o valor-p foi maior que 0,05 . Sendo assim, é possível afirmar, que apenas as intervenções em grupo não foram suficientes para atender as habilidades matemáticas, as quais estavam em prejuízo e necessitavam ser potencializadas e reabilitadas, em se tratando da leitura dos números.

Tabela 2 - Teste $t$ para o Teste de Transcodificação - leitura - pré-teste com pós-teste

2: Grupo controle

\begin{tabular}{llccc}
\hline & Média & $\begin{array}{c}\text { Número de } \\
\text { participantes }\end{array}$ & $\begin{array}{c}\text { Desvio } \\
\text { padrão }\end{array}$ & Valor-p (<0,05) \\
\hline Pré-teste & 3,25 & 4 & 2,22 & 0,04 \\
Pós-teste 2 & 1 & 4 & 0,82 & \\
\hline
\end{tabular}

Fonte: Elaborado pelas autoras.

Já em relação à Tabela 2, considerando apenas os quatro participantes da pesquisa, os quais permaneceram com indícios de DD, mesmo depois da realização das intervenções em grupo, verifica-se que quando considerado os resultados do pré-teste com o pós-teste 2 , com base no valor-p, estatisticamente é possível afirmar que as crianças tiveram avanços em relação às habilidades matemáticas, as quais estavam debilitadas na leitura dos número.

Gráfico 2 - Total de números com erros no Teste de Transcodificação - escrita - pré-teste com pós-teste 1 e 2: Grupo controle

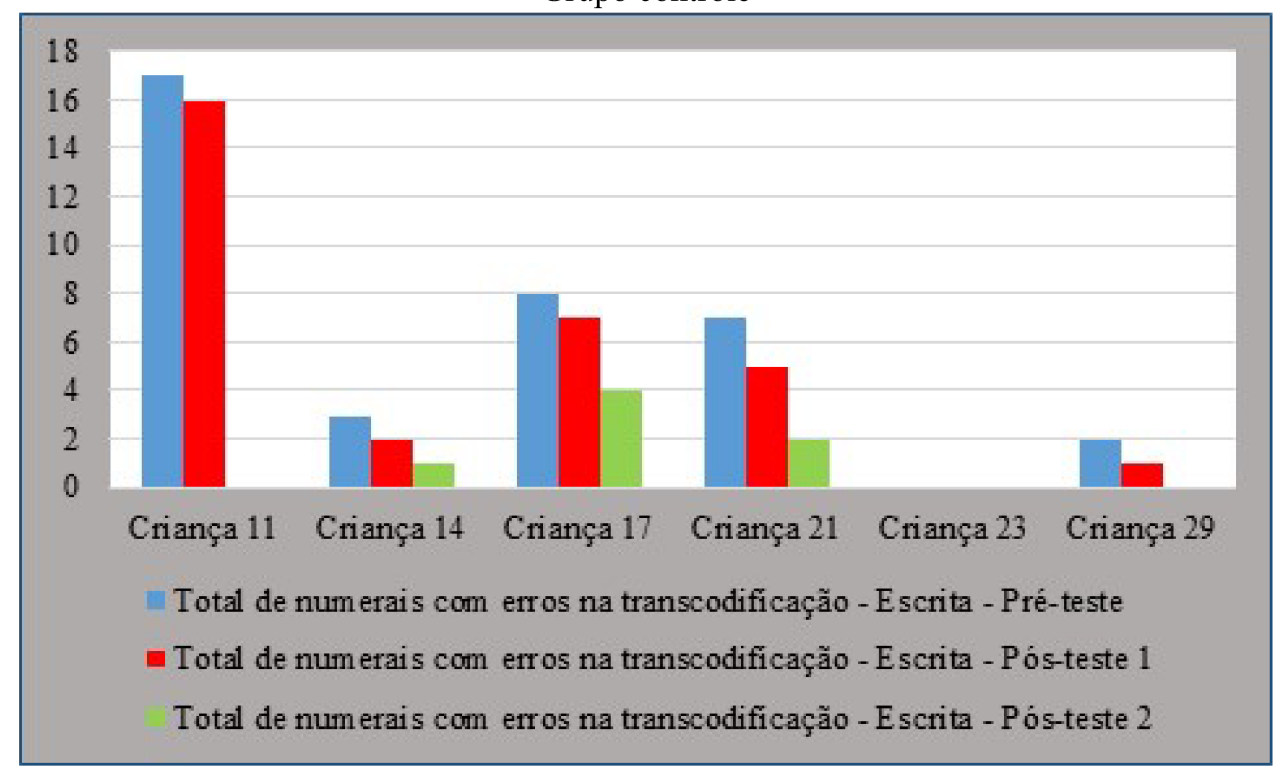

Fonte: Elaborado pelas autoras.

Com exceção das crianças 11 e 29 , que não foram até o final da pesquisa, por questões já destacadas anteriormente, observou-se que as crianças 14,17 e 21 obtiveram um declive maior no número de erros na escrita dos números, após a realização das intervenções psicopedagógicas individuais, verificando-se, assim, que as intervenções realizadas com essas crianças portadoras de indícios de DD foram eficazes para reabilitar as habilidades matemáticas em prejuízo e potencializar as habilidades preservadas. 
A importância das intervenções com crianças portadoras desse transtorno, são destacadas por Haase et al. (2011), ao salientarem um dos critérios de diagnóstico de DD, seria a resposta à intervenção - RI, em que o estudante é submetido a um processo de avaliação, intervenção e reavaliação.

Com a intenção de validar as hipóteses levantadas e apontadas na análise do Gráfico 2, elaborou-se as Tabelas 3 e 4, apresentando os resultados obtidos por meio do Teste $t$ para amostras pareadas, adotando como valor de significância para limiares de $t$ a probabilidade $<5 \%$.

Tabela 3 - Teste de Transcodificação - escrita - pré-teste com pós-teste 1: Grupo controle

\begin{tabular}{ccccc}
\hline & Média & $\begin{array}{c}\text { Número de } \\
\text { participantes }\end{array}$ & $\begin{array}{c}\text { Desvio } \\
\text { padrão }\end{array}$ & Valor-p (<0,05) \\
\hline Pré-teste & 6,17 & 6 & 6,11 & 0,005 \\
\hline Pós-teste 1 & 5,17 & 6 & 5,91 & \\
\hline
\end{tabular}

Fonte: Elaborado pelas autoras.

Por meio da Tabela 3, nota-se que após o período das intervenções psicopedagógicas em grupo, quando comparado os resultados do pré-teste com o pós-teste 1, que não houve diferenças significativas no desempenho das crianças do grupo controle, pois o valor-p foi maior que 0,05 . Portanto, é possível afirmar que as intervenções em grupo não atenderam as dificuldades específicas de cada uma das crianças, quanto à escrita dos números.

Tabela 4 - Teste $t$ para o Teste de Transcodificação - escrita - pré-teste com pós-teste

\begin{tabular}{ccccc} 
2: Grupo controle & Média & $\begin{array}{c}\text { Número de } \\
\text { participantes }\end{array}$ & $\begin{array}{c}\text { Desvio } \\
\text { padrão }\end{array}$ & Valor-p (<0,05) \\
\hline Pré-teste & 4,5 & 4 & 3,70 & 0,04 \\
Pós-teste 2 & 1,75 & 4 & 1,70 & \\
\hline
\end{tabular}

Fonte: Elaborado pelas autoras.

Referente à Tabela 4, na qual foram considerados apenas os quatro participantes da pesquisa que deram continuidade aos atendimentos individualmente, baseando-se no valor-p, percebe-se que quando comparado os resultados do pré-teste com o pós-teste 2, as crianças apresentaram um declive no número de erros no Teste de Transcodificação em relação a escrita dos números. Sendo assim, é possível destacar que as crianças do grupo controle, apresentaram avanços significativos, após o período das intervenções psicopedagógicas individuais.

Uma análise mais detalhada dos resultados das crianças do grupo controle, no que tange ao Teste de Transcodificação (MOURA et al., 2013), sugere como hipótese que as crianças apresentaram dificuldades acentuadas na transcodificação numérica, pois conforme os apontamentos de Kosc (1974), a transcodificação está relacionada às falhas das habilidades da Discalculia verbal, Discalculia lexical e Discalculia gráfica, e crianças com Dislexia tendem a apresentar dificuldades, principalmente em relação às habilidades relacionadas à 
Discalculia gráfica. Porém, mesmo diante das dificuldades, foi possível observar que as crianças do grupo controle apresentaram melhoras em seu desempenho, após as intervenções psicopedagógicas realizadas.

Para ilustrar e sintetizar as modificações no desempenho das crianças do grupo experimental submetidas às intervenções psicopedagógicas, elaboraram-se os Gráficos 3 e 4 .

Gráfico 3 - Total de números com erros no Teste de Transcodificação - leitura - pré-teste com pós-teste 1: Grupo experimental

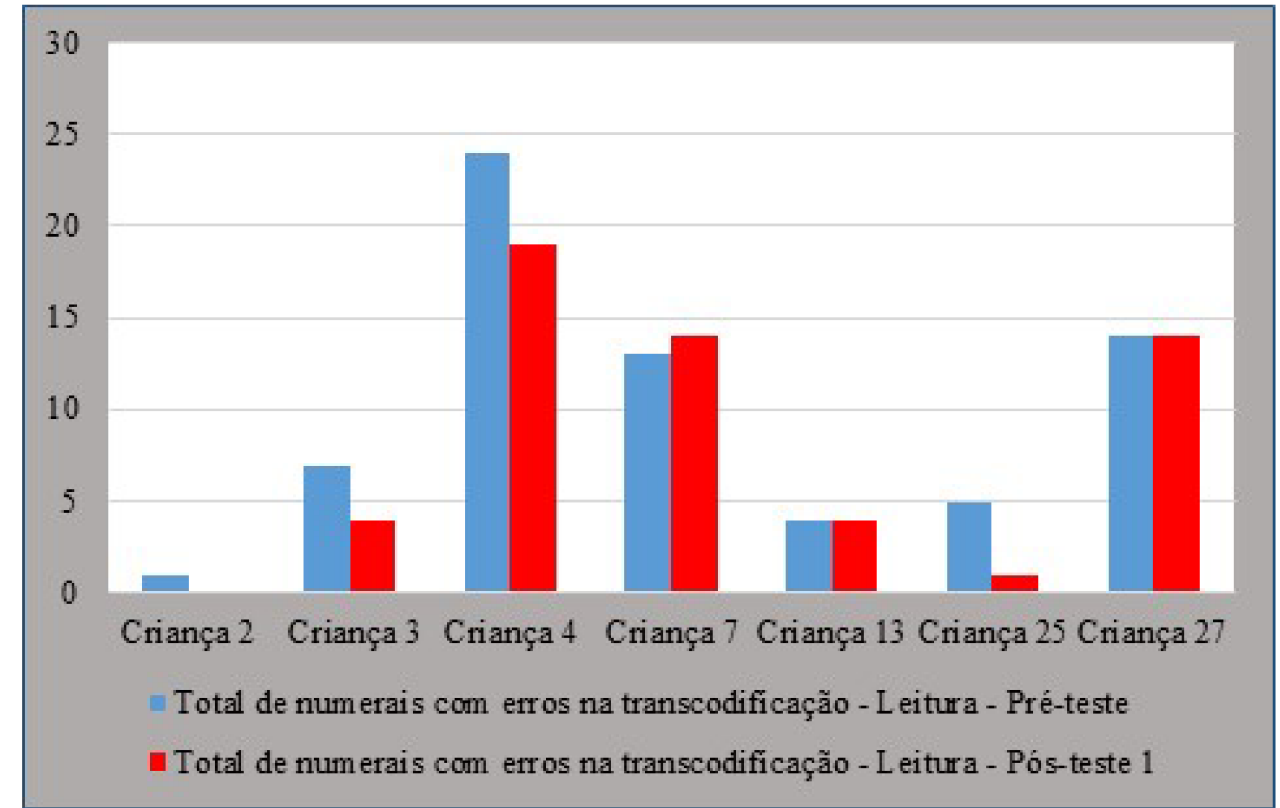

Fonte: Elaborado pelas autoras.

A partir dos dados expostos no Gráfico 3, é possível verificar que as crianças de modo geral, apresentaram um declive no número de erros na leitura dos números, após as intervenções. Contudo, as crianças 4, 7 e 27, mesmo diante de outros avanços, permanecerem com um índice de erros elevados na transcodificação, o que possibilita ter como hipótese diagnóstica, dessas três crianças, indícios de Discalculia verbal.

Com a intenção de validar as hipóteses levantadas e apontadas na análise do Gráfico 3 , elaborou-se a Tabela 5, apresentando os resultados obtidos por meio do Teste $t$ para amostras pareadas, assumindo como nível de significância $<5 \%$.

Tabela 5 - Teste $t$ para o Teste de Transcodificação - leitura - pré-teste com pós-teste

1: Grupo experimental

\begin{tabular}{ccccc}
\hline & Média & $\begin{array}{c}\text { Número de } \\
\text { participantes }\end{array}$ & $\begin{array}{c}\text { Desvio } \\
\text { padrão }\end{array}$ & Valor-p (<0,05) \\
\hline Pré-teste & 9,71 & 7 & 7,87 & 0 \\
Pós-teste 1 & 8 & 7 & 7,50 & 0,047 \\
\hline
\end{tabular}

Fonte: Elaborado pelas autoras.

Após o período das intervenções individuais realizadas com o grupo experimental, ao comparar os resultados do Teste de Transcodificação, referente à leitura dos números, no préteste e no pós-teste 1, na Tabela 5, baseando-se no valor-p encontrando, sendo menor que 0,05 , é possível verificar que as crianças apresentaram avanços em seu desempenho, sendo 
possível potencializar e reabilitar as habilidades matemáticas em prejuízo na leitura dos números, por meio dos jogos utilizados no período de intervenção psicopedagógica.

Gráfico 4 - Total de números com erros no Teste de Transcodificação - escrita - pré-teste com pós-teste 1: Grupo experimental

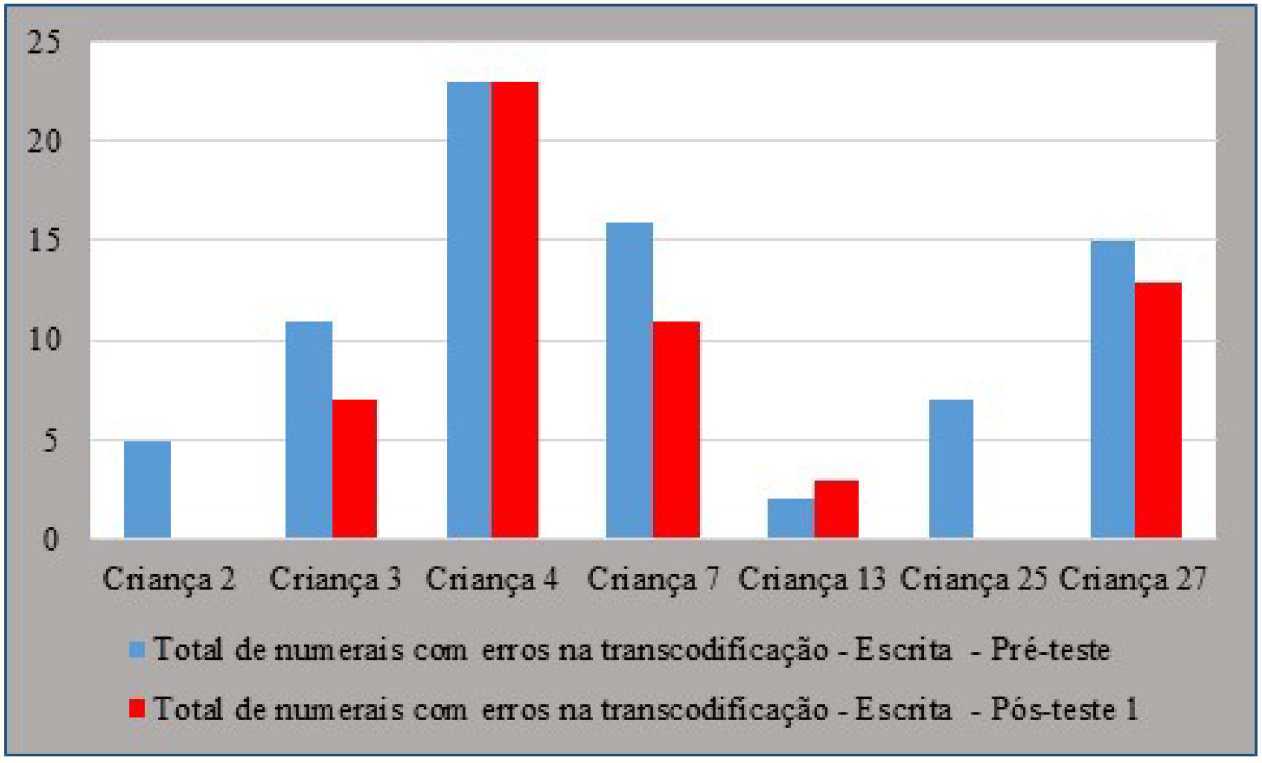

Fonte: Elaborado pelas autoras.

Por meio do Gráfico 4, fica evidente que houve melhoras de modo geral, em se tratando da escrita dos números nesse grupo de crianças, após as intervenções psicopedagógicas, reduzindo assim, o número de erros na transcodificação, com exceção da criança 4 que não teve avanço algum, mantendo-se com um índice de erros elevado e da criança 13 que apresentou um número maior de erros em seu pós-teste.

Com a intenção de validar as hipóteses levantadas e apontadas na análise do Gráfico 4, elaborou-se a Tabela 6, apresentando os resultados obtidos por meio do Teste $t$ para amostras pareadas, adotando como valor de significância para limiares de $t$ a probabilidade $<5 \%$.

Tabela 6 - Teste $t$ para o Teste de Transcodificação - escrita - pré-teste com pós-teste

1: Grupo experimental

\begin{tabular}{ccccc}
\hline & Média & $\begin{array}{c}\text { Número de } \\
\text { participantes }\end{array}$ & $\begin{array}{c}\text { Desvio } \\
\text { padrão }\end{array}$ & Valor-p (<0,05) \\
\hline Pré-teste & 11,29 & 7 & 7,27 & 0,01 \\
Pós-teste 1 & 8,14 & 7 & 8,30 & \\
\hline
\end{tabular}

Fonte: Elaborado pelas autoras.

Ao analisar o valor-p da Tabela 6, considerando os resultados do pré-teste com o pós-teste 1, é possível afirmar que as crianças tiveram avanços em relação as habilidades matemáticas, as quais estavam debilitadas na escrita dos números, após os jogos utilizados nos atendimentos individuais, proporcionando reabilitar e potencializar as habilidades matemáticas.

Com base em uma análise detalhada do desempenho das crianças, as quais participaram do grupo experimental, é possível verificar que em relação ao Teste de 
Transcodificação (MOURA et al., 2013), apresentaram um declive no número de erros, em relação à leitura e à escrita dos números, após o período de intervenção psicopedagógica. Entretanto, nem todas as crianças apresentaram melhoras significativas referente às habilidades de transcodificação, pois é necessário um número maior de intervenções focadas na habilidade que precisa ser reabilitada.

\section{Considerações finais}

Este artigo teve como objetivo apresentar os resultados verificados, por meio do Teste de Trancodificação (MOURA et al., 2013), o qual foi utilizado como um dos instrumentos de avaliação psicopedagógica, com o objetivo "Analisar a repotencialização de habilidades matemáticas relacionadas à transcodificação numérica, em crianças com indícios de Discalculia, após o período de intervenções psicopedagógicas”.

Com base nos dados coletados, após o período de intervenções psicopedagógicas, com as crianças do grupo controle e do grupo experimental, pode-se verificar que as crianças com hipótese diagnóstica de DA em leitura e escrita e com Dislexia, apresentaram dificuldades acentuadas na transcodificação numérica, pois conforme Kosc (1974), a transcodificação está relacionada a falhas nas habilidades matemáticas referentes à Discalculia verbal, à Discalculia lexical e à Discalculia gráfica. Todavia, mesmo diante das dificuldades apresentadas, foi possível observar que as crianças de ambos os grupos apresentaram um declive no número de erros em relação à leitura e à escrita dos números, após as intervenções psicopedagógicas realizadas.

Contudo, as melhoras no desempenho da Matemática apresentado por essas crianças, ainda não foram suficientes para descartar a possibilidade da DD. No que concerne ao diagnóstico, Haase et al. (2011) apontam que se após o período de aproximadamente um ano ou considerando o desempenho na RI, o estudante persistir com as dificuldades, é possível constatar a presença ou não desse transtorno.

Vale destacar que para este estudo é perceptível que os avanços no desempenho em Matemática, foram decorrentes dos jogos desenvolvidos durante o período das intervenções realizadas individualmente com cada uma das crianças, proporcionando que por meio do lúdico, fossem abordadas as dificuldades específicas na leitura e na escrita dos números.

Diante disso, acredita-se ser recomendável ampliar as pesquisas referentes à transcodificação numérica em crianças com indícios de DD, realizando as intervenções psicopedagógicas com uma amostra maior de crianças e por um período de no mínimo um ano, devido ao seu grau de importância com vistas a identificar possíveis intervenções psicopedagógicas que possam oportunizar avanços em relação às habilidades cognitivas em 
defasagens, potencializando as habilidades existentes, minimizando assim, as dificuldades dessas crianças.

\section{Referências}

AVILA, L. A. B Avaliação e intervenções psicopedagógicas em crianças com indícios de Discalculia. Porto Alegre, 2017. Dissertação (Mestrado) - Pontifícia Universidade Católica do Rio Grande do Sul, 2017.

AVILA, L. A. B.; LARA, I. C. M. Discalculia: Um mapeamento de artigos brasileiros. Abakós. v. 6, p. 35-56, 2017.

BARROUILLET, P.; CAMOS, V.; PERRUCHET, P.; SERON, X. ADAPT: Developmental, Asemantic, and Procedural Model for Transcoding From Verbal to Arabic Numerals. Psychological Review, v. 111, n. 2, p. 368-394, 2004.

BASTOS, J. A. Discalculia: transtorno específico da habilidade em matemática. In: ROTTA, N.; OHLWEILER, L.; RIESCO, R. (Orgs). Transtornos da aprendizagem: Abordagem neurobiológica e multidisciplinar. São Paulo: Artes Médicas, 2006, p. 195- 206.

CRESWELL, J. W. Projeto de pesquisa: Métodos qualitativo, Quantitativo e Misto. 3.ed. Porto Alegre: Artes médicas, 2010.

DEHAENE, S.; COHEN, L. Towards an Anatomical and Functional Model of Number Processing. Mathematical Cognition, v. 1, p. 83-120, 1995.

DSM-5. Manual diagnóstico e estatístico de transtornos mentais. 5. ed. Porto Alegre: Artes Médicas, 2014.

FLICK, U. Uma introdução à pesquisa qualitativa. 2. ed. Porto Alegre: Bookman, 2007.

FREITAS, N. L.; FERREIRA, F. O.; HAASE, V. G. Aspectos linguísticos envolvidos na habilidade de transcodificar entre diferentes representações de número. Ciências \& Cognição, v. 17, n. 1, p. 01-15, 2012.

GERSTMANN, J. Some notes on the Gerstmann syndrome. Neurology, p. 866-869, 1957.

GIL, A. C. Como elaborar projetos de pesquisa. 5. ed. São Paulo: Atlas, 2010.

HAASE, V. G.; MOURA, R. J.; CHAGAS, P. P.; WOOD, G. Discalculia e Dislexia: Semelhanças Epidemiológica e Diversidade de Mecanismos Neurocognitivos. In: ALVES, L. M; MOUSINHO, R.; CAPELLINI, S. A. (Orgs). Dislexia: Novos temas, novas perspectivas, Publisher: Rio de Janeiro: Wak, 2011, p. 257-282.

HAINAUT, L. D'. Conceitos e métodos da estatística. v. 1. 2 ed., Fundação Calouste Gulbenkian: Lisboa, 1997.

KOSC, L. Developmentol Dyscalculia. Journal of Learning Disabilities can be found at, v. 7, n. 3, p.163-177, 1974. 
LARA. I. C. M. Jogando com a Matemática na Educação Infantil e séries iniciais. São Paulo: Editora Rêspel, 2005.

MCCLOSKEY, M., CARAMAZZA, A.; BASILI, A. Cognitive mechanisms in number processing and calculation: Evidence from dyscalculia. Brain and Cognitive, n. 4, p. 171-196, 1985.

MOURA, R.; WOOD, G.; CHAGAS-PINHEIRO, P.; LONNEMANN, J.; KRINZINGER, H.; WILLMES, K.; HAASE, V. G. Transcoding abilities in typical and atypical mathematics achievers: The role of working memory and procedural and lexical competencies. Journal of Experimental Child Psychology, p. 707-727, 2013.

MYKLEBUST, H. R.; JOHNSON, D. J. Dyslexia in Chindren. Exceptional Children, p. 14$25,1962$.

SILVA, J. B. L.; MOURA, R. J.; WOOD, G.; HAASE, V. G. Processamento Fonológico e Desempenho em Aritmética: Uma Revisão da Relevância para as Dificuldades de Aprendizagem. Trends in Psychology / Temas em Psicologia, v. 23, n. 1, 157-173, 2015.

STEIN, L. M. TDE: Teste de Desempenho Escolar: Manual para aplicação e interpretação. São Paulo: Casa do Psicólogo, 1994.

WECHSLER, D. WISC-III: Escala de Inteligência Wechsler para crianças: Manual. $3^{\mathrm{a}}$ ed.; São Paulo: Casa do Psicólogo, 2002, p. 309.

YIN, R. K. Estudo de caso: Planejamento e métodos. 4. ed. Porto Alegre: Bookman, 2010.

\section{SOBRE AS AUTORAS}

LANÚZIA ALMEIDA BRUM AVILA. Doutoranda em Educação em Ciências e Matemática pela Pontifícia Universidade Católica do Rio Grande do Sul (2018). Bolsista CAPES. Mestra em Educação em Ciências e Matemática pela Pontifícia Universidade Católica do Rio Grande do Sul (2017). Especialista em Psicopedagogia Clínica e Institucional pela Faculdade Porto-Alegrense de Educação, Ciências e Letras (2007). Graduada em Pedagogia Orientação Educacional pela Faculdade Porto-Alegrense de Educação, Ciências e Letras (2003). Tem experiência na área de Educação, atuando principalmente nos seguintes temas: cognição e aprendizagem; transtorno bipolar; dificuldades de aprendizagem em leitura, escrita e matemática; transtornos de aprendizagem: Dislexia e Discalculia do Desenvolvimento.

ISABEL CRISTINA MACHADO DE LARA. Doutora em Educação pela Universidade Federal do Rio Grande do Sul (2007), Mestre em Educação pela Universidade Federal do Rio Grande do Sul (2001) e possui graduação em Matemática - Licenciatura Plena pela Universidade Federal do Rio Grande do Sul (1993). Pós-Doutoramento em Educação em Ciências e Matemática pela Pontifícia Universidade Católica do Rio Grande do Sul (2011). Professora permanente no Programa de Pós-Graduação em Educação em Ciências e Matemática e da Escola Politécnica da Pontifícia Universidade Católica do Rio Grande do Sul. Coordena o Grupo de Estudos e Pesquisas sobre Discalculia do Desenvolvimento GEPEDPUCRS - e o Grupo de Estudos e Pesquisas sobre Etnomatemática - GEPEPUCRS. Realiza palestras, oficinas e cursos de extensão atuando principalmente nos seguintes temas: ensino e aprendizagem da Matemática desde a Educação Infantil; Neurociências e aprendizagem em Matemática; uso de jogos; Etnomatemática; Resolução de Problemas; História da Matemática; Modelagem Matemática. 
Recebido: 17 de outubro de 2018.

Revisado: 17 de setembro de 2019.

Aceito: 14 de novembro de 2019 . 